\title{
Revisão
}

\section{Associação entre líquen plano e o vírus da hepatite C: Um estudo de metanálise}

\author{
Moises Rodrigues Rocha ${ }^{a}$, Liliane Lins ${ }^{b, *}$, Ana Carolina Cattony ${ }^{a}$ \\ ${ }^{a}$ Escola Bahiana de Medicina e Saúde Pública, Salvador, Brasil \\ ${ }^{b}$ Faculdade de Medicina da Bahia, Universidade Federal da Bahia, Salvador, Brasil
}

INFORMAÇÃO SOBRE O ARTIGO

\section{Historial do artigo:}

Recebido a 15 de October de 2017

Aceite a 8 de June de 2018

On-line a 22 de June de 2018

\section{Palauras-chave:}

Associação

Hepatite C

Líquen plano

Metanálise

\section{R E S U M O}

Objetivo: Desenvolver uma revisão sistemática da literatura com metanálise para avaliar a associação de infeção pelo vírus da hepatite C (HCV) em pacientes com Líquen Plano (LP). Métodos: Foi realizada uma pesquiza nas bases de dados MEDLINE, LILACS, Cochrane e ISI Web of Knowledge, utilizando os descritores "Hepatitis C" e "Lichen Planus". Foram selecionados os resumos de estudos de caso controle abordando a infeção de HCV em pacientes com LP. Foram analisados os estudos que confirmavam a sorologia anti-HCV com testes confirmatórios (PCR e RIBA). Foi realizada a análise do Odds Ratio (OR), DerSimonian-Laird, utilizando-se o programa BioEstat 5.3.

Resultados: 15 estudos foram incluídos, cuja metanálise evidenciou que, em pacientes com LP, a existência de HCV é aproximadamente 3,54 vezes maior que em não portadores de LP (OR 3,54; CI 95\%: 2,31 a 5,44; $\mathrm{p}<0,0001$ ).

Conclusão: A presente revisão com metanálise demonstrou associação entre as duas patologias. (Rev Port Estomatol Med Dent Cir Maxilofac. 2018;59(1):2-9)

( 2018 Sociedade Portuguesa de Estomatologia e Medicina Dentária. Publicado por SPEMD. Este é um artigo Open Access sob uma licença CC BY-NC-ND (http://creativecommons.org/licenses/by-nc-nd/4.0/).

* Autor correspondente.

Correio eletrónico: liliane.lins@ufba.br (Liliane Lins).

http://doi.org/10.24873/j.rpemd.2018.06.220

1646-2890/@ 2018 Sociedade Portuguesa de Estomatologia e Medicina Dentária. Published by SPEMD.

This is an open access article under the CC BY-NC-ND license (http://creativecommons.org/licenses/by-nc-nd/4.0/). 


\title{
Lichen planus and hepatitis $C$ virus association: A meta-analysis study
}

\author{
A B S T R A C T
}

Keywords:

Association

Hepatitis C

Lichen planus

Meta-analysis
Objective: To develop an integrative review of the literature with meta-analysis to evaluate the association between hepatitis C virus (HCV) infection and patients with lichen planus (LP).

Methods: We searched the MEDLINE, LILACS, Cochrane and ISI Web of Knowledge databases, using the keywords "Hepatitis C" and "Lichen Planus." We selected the abstracts of case-control studies addressing HCV infection in patients with LP. We included studies that confirmed the anti-HCV serology by confirmatory tests (PCR and RIBA). We performed an odds ratio (OR) analysis based on the DerSimonian-Laird method, using the BioEstat 5.3 software.

Results: 15 studies were included, whose meta-analysis showed that the incidence of HCV in patients with LP was approximately 3.54 times higher than in patients without LP (OR 3.54; 95\% CI: 2.31-5.44 p<0.0001).

Conclusion: The present review with meta-analysis showed an association between the two pathologies. (Rev Port Estomatol Med Dent Cir Maxilofac. 2018;59(1):2-9)

(c) 2018 Sociedade Portuguesa de Estomatologia e Medicina Dentária. Published by SPEMD. This is an open access article under the CC BY-NC-ND license (http://creativecommons.org/licenses/by-nc-nd/4.0/).

\section{Introdução}

A partir da identificação do Vírus da Hepatite C (HCV) no ano de 1989, estudos foram feitos com o objetivo de buscar uma relação entre a infeção por este vírus e as manifestações extra-hepáticas, dentre elas, o Líquen Plano (LP). ${ }^{1-2}$ Algumas manifestações, a exemplo da glomerulonefrite membranoproliferativa, púrpura cutânea tarda e da crioglobulinemia já foram bem estabelecidas, ${ }^{4}$ entretanto, outras relações como a associação entre o LP, ainda necessitam de mais estudos.

O líquen plano é uma doença mucocutânea inflamatória crónica, mediada principalmente por células T CD4+, de causa desconhecida e caracterizada, na maioria dos casos (60-70\%), por erupções papulosas ou placas de aparência reticulada. ${ }^{5} \mathrm{O}$ LP se apresenta através de lesões autolimitadas (cutâneas) e orais, que são crónicas, de cura espontânea rara e dividas em seis formas: erosiva, reticular, atrófica, bolhosa, papular e em placa. ${ }^{6}$ O diagnóstico do LP é clínico e histopatológico, observado pela liquefação da camada basal do epitélio, associado ao infiltrado inflamatório na junção do epitélio com a lâmina própria. $^{5}$

É estimado que a Hepatite C afeta cerca de 130 a 150 milhões de pessoas em todo o mundo, variando a incidência e prevalência entre os continentes. ${ }^{7}$ A forma de transmissão do HCV pode ocorrer por via vertical, parenteral e sexual, em pouca frequência. ${ }^{8}$ A Hepatite $C$ é uma inflamação no fígado provocada por um vírus RNA, da família flaviviridae, que quando crónica, pode conduzir a insuficiência hepática, cirrose e cancro. Associada a estas manifestações, a infeção pelo HCV pode cursar com manifestações extra-hepáticas de caráter autoimune, devido a formação de imunocomplexos, ${ }^{9}$ além de ter importante fator oncogénico dos hepatocarcinomas. ${ }^{8}$
Alguns estudos avaliaram a prevalência do Vírus da Hepatite C em pacientes com Líquen Plano e vice-versa, entretanto, os resultados são controversos em vários locais do mundo. ${ }^{10}$ A frequência de anticorpos anti-HCV em pacientes com LP cutâneo e oral variam na literatura de $4 \%$ a $65 \%$, a exemplo. ${ }^{11}$ Os relatos indicam que o HCV está mais relacionado a manifestações mucosas que as lesões cutâneas.

Existe uma distribuição heterogénea dos genótipos do HCV no mundo, o que foi um fator influenciador nas manifestações clinicas da hepatite C e no desenvolvimento do LP, entretanto esta relação ainda não está bem estabelecida. ${ }^{12}$ Além disso, tem sido descrito na literatura a associação do tratamento da hepatite C com interferon e o surgimento ou agravamento das lesões do LP. ${ }^{13-15}$ Porém, não é possível a afirmação se o VCH, o tratamento para hepatite C ou os dois estão diretamente relacionados com o LP.

$\mathrm{Na}$ maioria dos casos, tanto a fase aguda quanto a fase crónica da infeção pelo HCV são assintomáticas ou oligossintomaticas, fazendo com que o paciente só tenha o diagnostico na fase tardia da doença, quando as complicações já estão presentes. Assim, reconhecer manifestações extra-hepáticas como o Líquen Plano pode tornar uma ferramenta fundamental para o diagnóstico e tratamento previamente ao surgimento das complicações tardias. Além disso, se o estudo evidenciar relações entre as patologias, o tratamento do LP em pacientes portadores de HCV pode ser sistematizado e melhorado, afim de reduzir a morbidade destes pacientes.

Com o estabelecimento da hipótese da associação entre o LP e a infeção do indivíduo pelo HCV, muitos estudos têm sido publicados e os resultados se mostram controversos. Alguns trabalhos demonstram a associação entre as duas patologias e outros não corroboram com esta associação. A inclusão em revisões sistemáticas de estudos que não fizeram confirmação 
da sorologia para o HCV por meio de métodos diagnósticos como RIBA (Recombinant Immunoblot Assay) ou PCR (Polymerase Chain Reaction) contribuem para vieses nos estudos que utilizam a referida metodologia. A partir desta lacuna na literatura, este estudo tem como objetivo avaliar se existe a associação entre a infeção pelo Vírus da Hepatite C e o Líquen Plano por meio de uma revisão sistemática que incluem estudos de caso-controle com diagnóstico de LP e HCV.

\section{Métodos}

Foi realizado uma busca nas bases de dados MEDLINE (<http:// www.ncbi.nlm.nih.gov/pubmed/clinical>), LILACS (<http://lilacs.bvsalud.org >) e Cochrane (<http://www.thecochranelibrary.com>), utilizando-se os seguintes descritores "Hepatitis C" and "Lichen Planus" no período de Abril a Maio de 2016. Foram selecionados estudos de caso-controle que buscaram evidencias de associação entre as duas patologias. Os autores também avaliaram as referências bibliográficas dos estudos incluídos e resumos de conferências na base de dados ISI Web of Knowledge (<www.isiknowledge.com $>$ ).

Foram incluídas pesquisas de caso-controle sem restrição de tempo e idioma que pesquisaram a infeção pelo HCV em portadores de líquen plano (LP) e em grupos que no diagnóstico de LP foi realizada análise histopatológica, seguido de diagnóstico de HCV.

Considerando que a presente revisão incluiu exclusivamente artigos de caso-controle, optou-se pela utilização das diretrizes da iniciativa Equator, especificamente a recomendação STROBE, para selecionar artigos que apresentaram maior transparência em sua descrição. Esta iniciativa apresenta recomendações sobre o que deve ser incluído em uma descrição mais precisa e completa de estudos observacionais, sendo utilizado 22 itens. Os autores determinaram um ponto de corte de $70 \%$ de preenchimento dos critérios para inclusão dos estudos.

Foram excluídos os artigos que não possuíam o critério de confirmação sorológica do HCV com RIBA ou PCR. As dúvidas em relação à inclusão e exclusão foram decididas pelos pesquisadores envolvidos.

Os dados relevantes para o trabalho foram: método diagnóstico e confirmatório do HCV, diagnóstico e característica do LP. Foram acedidas também as informações sobre a população de cada estudo (número de pessoas, sexo, idade casos e dos controles). Todos os artigos triados por meio dos resumos, tiveram sua elegibilidade confirmada pela leitura detalhada do texto completo do artigo. A confirmação da elegibilidade foi realizada por dupla de revisores independentes. Utilizou-se ficha detalhada padronizada contendo os critérios de inclusão estabelecidos. Quando houve discordância entre os revisores, as mesmas foram resolvidas por consenso.

A metanálise foi realizada através do programa BioEstat 5.3, utilizando a análise estatística de Efeito Aleatório de DerSimonian-Laird, por considerar a possibilidade de heterogeneidade dos estudos. Os dados obtidos estão descritos em tabela. O Odds Ratio (OR) e o Intervalo de Confiança de 95\% (IC 95\%) de cada estudo foram calculados individualmente para, em seguida, realizar a combinação dos estudos selecionados.

\section{Resultados}

Foram encontrados 650 artigos na busca nas bases de dados do MEDLINE (374), LILACS (23) e Cochrane (253) e 16 resumos de conferências no ISI Web of Knowledge. Foram excluídos 483 artigos através do tipo de estudo, 96 por estar fora do escopo do estudo, 49 por não se tratar de estudo de caso-controle, um por não ter metodologia devidamente esclarecida, um por tratar de prevalência de LP em pacientes VHC+ e quatro devido a ausência do teste confirmatório por RIBA ou PCR. Os 16 resumos também foram excluídos por não se tratar de caso-controle. Então, quinze estudos se enquadravam nos critérios de inclusão da pesquisa proposta (Figura 1).

Todos os artigos incluídos ${ }^{6,10,15-27}$ foram organizados em uma tabela (Tabela 1), contendo a prevalência do Vírus da Hepatite $C$ nos pacientes com Líquen Plano e nos grupos controle, sendo feito a análise dos dados contidos. De acordo com a análise, o número total de pacientes com Líquen Plano incluídos nos 15 estudos foi de 2513, enquanto que no grupo controle o número total de pacientes foi de 3162. Nos pacientes com Líquen Plano, a frequência geral de anticorpos anti-HCV, que receberam confirmação por PCR foi de 16,8\%, enquanto que no grupo controle foi de $6,4 \%$.

Todos os 15 artigos incluídos estavam redigidos em inglês. Dois estudos foram conduzidos na Espanha, ${ }^{15,19}$ dois na França, ${ }^{21,23}$ e no Iran, ${ }^{18,27}$ um no Reino Unido ${ }^{26}$ e um estudo em cada país: Alemanha, ${ }^{24}$ Inglaterra, ${ }^{25}$ Eslovênia, ${ }^{10}$ Japão ${ }^{16}$ e Índia. ${ }^{17}$ Três trabalhos foram conduzidos na Itália, ${ }^{6,20,22}$ entretanto, como Campisi et al. ${ }^{20}$ analisaram duas diferentes regiões da Itália (Campania e Sicilia), este estudo aparece dividido, de acordo com as regiões, para melhor entendimento e visualização dos resultados, recebendo as numerações 10 e 11 respetivamente. Com a segmentação do estudo de Campisi et al., ${ }^{20}$ apesar de terem sido 15 artigos selecionados, a numeração da tabela corresponde a 16.

Todos os artigos incluídos eram de caso-controle, onde todos os casos analisados levaram em consideração o diagnóstico histopatológico do LP. Em cinco estudos foram excluídos do grupo de LP os pacientes que faziam uso de medicação cujas reações adversas poderiam incluir reação liquenóide. ${ }^{10,17,21,22,25}$ e lançaram mão de achados histopatológicos como queratinização sobrejacente, infiltração linfocitária no tecido e degeneração das camadas basais para auxiliar no diagnóstico. Outro estudo ${ }^{18}$ excluiu todos os pacientes com LP que tinham possibilidade de reação liquenóide por uso de drogas ou restauração dental. A presença dos anticorpos anti-HCV dos estudos foi confirmada, na maioria dos casos, por RIBA de segunda geração, ${ }^{6,19-22}$ seguido pelo RIBA de terceira geração ${ }^{10,23,25}$ e PCR, por último. ${ }^{15-18,24}$ O estudo realizado no Reino Unido ${ }^{26}$ não necessitou de confirmação pelos métodos por não apresentar indivíduos com o HCV positivo.

Os pacientes que formavam os grupos controle, em cinco dos estudos incluídos, eram pacientes com outras dermatoses, exceto LP, ${ }^{10,15,21,24,25}$ em um estudo, pessoas da população geral, saudáveis, formaram o grupo controle, ${ }^{16,20}$ um trabalho teve como grupo controle pacientes com queratose oral, ${ }^{22}$ um com pacientes submetidos à procedimento cirúrgico, ${ }^{23} \mathrm{um}$ com pacientes com urticária, ${ }^{19}$ enquanto outro não esclareceu a característica do seu grupo controle. Dentre esses trabalhos, 


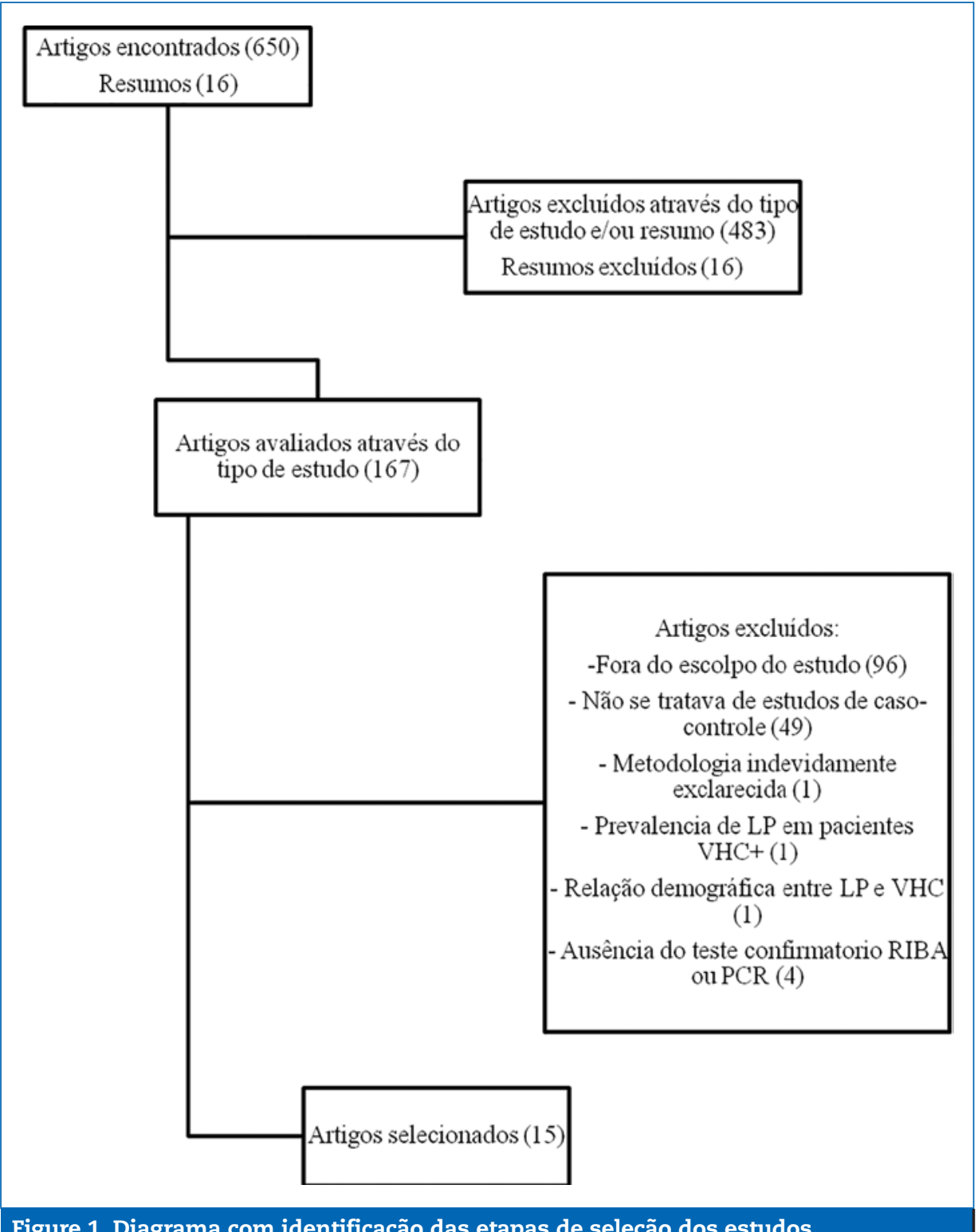

quatro fizeram escolha aleatória dos controles, ${ }^{10,15,21,25}$ quatros o fizeram por emparelhamento por sexo e idade, ${ }^{17,19,22,26}$ sendo que seis não deixaram claro o método de inclusão de pessoas no grupo controle. 6,16,18,20,23,24 No estudo realizado no Irão, ${ }^{18}$ os pacientes do grupo controle foram avaliados por dois dentistas para excluir lesões de LP e foram avaliados quanto ao passado ou história de hepatite viral, risco de contaminação, cirurgia prévia, consumo de álcool, uso de drogas intravenosa, história de tatuagem, abuso de drogas entre outros.

Os pacientes com LP eram, em sua maioria, compostos por mulheres em treze dos dezasseis estudos, , , 10,15-20,22,24-27 enquanto que os homens foram maioria, no grupo de LP, em um deles, ${ }^{21}$ sendo que um estudo não quantificou a relação de homens e mulheres nesse grupo. ${ }^{23} \mathrm{Em}$ relação ao grupo controle, as mulheres também foram maioria em oito dos trabalhos, ${ }^{10,15,16,18,19,22,24,26}$ contra apenas dois com predomínio de homens. ${ }^{21,25}$ Os grupos controle de quatro estudos não tiveram essas características descritas. ${ }^{6,17,20,23}$ A média de idade dos pacientes com LP foi igual ou superior a 50 anos em nove dos estudos $6,10,15,17,18,20,22,24,25$ e nos controles, em seis deles. ${ }^{15,17,21,22,24,25}$ (Tabela 2)

Para a avaliação dos estudos, optou-se pela utilização do STROBE, para selecionar artigos que apresentaram maior transparência em sua descrição. Foram incluídos aqueles que atingiram a pontuação maior que $70 \%$ no checklist STROBE.

Na metanálise, o resultado do Odds Ratio (OR) combinado dos estudos incluídos foi de 3,54, sendo o valor de $\mathrm{p}<0,0001$, dentro de um Intervalo de Confiança (IC) de 95\% (2,31 a 5,44), rejeitando-se a hipótese de nulidade. $O$ teste da heterogeneidade foi significativo ( $p=0,002)$, justificando o teste de escolha. A estimativa de risco de pacientes com LP apresentarem HCV é de 3,54 ( $p<0,0001)$. O OR, IC e peso de cada estudo, bem como OR e IC combinados, calculados pela análise de efeito aleatório de DerSimonian-Laird, estão descritos. (Figura 2) 
Tabela 1. Dados dos estudos incluídos.

\begin{tabular}{|c|c|c|c|c|c|c|c|c|}
\hline \multirow{2}{*}{ N. ${ }^{\circ}$} & \multirow{2}{*}{ Autor } & \multirow{2}{*}{ Ano } & \multirow{2}{*}{ País } & \multicolumn{2}{|c|}{ LP + } & \multicolumn{2}{|c|}{ Controle } & \multirow{2}{*}{$\begin{array}{c}\text { Teste } \\
\text { Confirmatório }\end{array}$} \\
\hline & & & & $\mathrm{HCV}+$ & HCV- & HCV+ & HCV- & \\
\hline 1 & Cribier et al. ${ }^{21}$ & 1994 & França & 2 & 50 & 3 & 109 & RIBA-2 \\
\hline 2 & Sanchez-Pérez et al. ${ }^{15}$ & 1996 & Espanha & 13 & 65 & 2 & 80 & PCR \\
\hline 3 & Carrozo et al. ${ }^{22}$ & 1996 & Itália & 19 & 51 & 3 & 67 & RIBA-2 \\
\hline 4 & Dupin et al. ${ }^{23}$ & 1997 & França & 5 & 97 & 14 & 292 & RIBA-3 \\
\hline 5 & Imhof et al. ${ }^{24}$ & 1997 & Alemanha & 12 & 72 & 1 & 86 & PCR \\
\hline 6 & Mignogna et al. ${ }^{6}$ & 1998 & Itália & 76 & 187 & 3 & 97 & RIBA-2 \\
\hline 7 & Ingafou et al. ${ }^{26}$ & 1998 & Reino Unido & 0 & 55 & 0 & 110 & 一 \\
\hline 8 & Tucker et al. ${ }^{25}$ & 1999 & Inglaterra & 0 & 45 & 1 & 31 & RIBA-3 \\
\hline 9 & Gimenez-Garcia et al. ${ }^{19}$ & 2003 & Espanha & 9 & 92 & 2 & 97 & RIBA-2 \\
\hline 10 & Campisi et al. ${ }^{20}$ & 2004 & Itália-Campânia & 189 & 511 & 79 & 409 & RIBA-2 \\
\hline 11 & Campisi et al. ${ }^{20}$ & 2004 & Itália-Sicília & 49 & 110 & 75 & 646 & RIBA-2 \\
\hline 12 & Stojanovic et al. ${ }^{10}$ & 2008 & Eslovênia & 2 & 171 & 0 & 218 & RIBA-3 \\
\hline 13 & Konidena e Pavani ${ }^{17}$ & 2011 & Índia & 3 & 22 & 0 & 25 & PCR \\
\hline 14 & Petti et al. ${ }^{27}$ & 2011 & Irão & 4 & 409 & 4 & 489 & RIBA-2 \\
\hline 15 & Nagao e Sata ${ }^{16}$ & 2012 & Japão & 35 & 24 & 14 & 71 & PCR \\
\hline 16 & Gerayli et al. ${ }^{18}$ & 2014 & Irão & 5 & 129 & 1 & 133 & PCR \\
\hline & TOTAL Combinado & & & 423 & 2090 & 202 & 2960 & \\
\hline
\end{tabular}

Tabela 2. Características demográficas dos grupos com LP e controle dos estudos incluídos.

\begin{tabular}{|c|c|c|c|c|c|c|c|}
\hline \multirow{2}{*}{ N. ${ }^{\circ}$} & \multirow{2}{*}{ Autor } & \multicolumn{3}{|c|}{$\mathrm{LP}+$} & \multicolumn{3}{|c|}{ Controle } \\
\hline & & F: $\mathbf{n} .^{\circ} / \%$ & M: $\mathbf{n} .^{\circ} / \%$ & MI & F: $\mathbf{n} .{ }^{\circ} / \%$ & M: $\mathbf{n} .^{\circ} / \%$ & MI \\
\hline 1 & Cribier et al. ${ }^{21, \dagger}$ & $22 / 42,3$ & $30 / 57,7$ & $\begin{array}{l}\text { F: } 58,5 \\
\text { M: } 47,5\end{array}$ & $46 / 41,1$ & $66 / 58,9$ & $\begin{array}{l}\text { F: } 59,8 \\
\text { M: } 54,1\end{array}$ \\
\hline 2 & Sanchez-Pérez et al. ${ }^{15}$ & $42 / 53,8$ & $36 / 46,2$ & 50 & $47 / 57,3$ & $35 / 42,7$ & 53 \\
\hline 3 & Carrozo et al. ${ }^{22}$ & $39 / 55,7$ & $31 / 44,3$ & 55,2 & $39 / 55,7$ & $31 / 44,3$ & 55,6 \\
\hline 4 & Dupin et al. ${ }^{23, a}$ & - & - & - & - & - & - \\
\hline 5 & Imhof et al. ${ }^{24}$ & $63 / 75,0$ & $21 / 25,0$ & 58,1 & $58 / 66,6$ & $29 / 33,3$ & 58,3 \\
\hline 6 & Mignogna et al. 6,b. & $156 / 59,3$ & $107 / 40,7$ & 55,5 & - & - & - \\
\hline 7 & Ingafou et al. ${ }^{26}$ & $44 / 80,0$ & $10 / 20,0$ & 46 & $86 / 78,2$ & $24 / 21,8$ & 39 \\
\hline 8 & Tucker et al. ${ }^{25}$ & $24 / 53,3$ & $21 / 46,7$ & 51,2 & $14 / 43,8$ & $18 / 56,2$ & 51,6 \\
\hline 9 & Gimenez-Garcia et al. ${ }^{19}$ & $57 / 56,4$ & $44 / 43,6$ & 48 & $69 / 69,7$ & $38 / 30,3$ & 46,6 \\
\hline 10 & Campisi et al. ${ }^{20, \mathrm{~b}}$ & $420 / 60,0$ & $280 / 40,0$ & 54,3 & - & - & - \\
\hline 11 & Campisi et al. ${ }^{20, b}$ & $111 / 69,8$ & $48 / 30,2$ & 54,3 & - & - & - \\
\hline 12 & Stojanovic et al. & $108 / 62,4$ & 65 / 37,6 & 50 & $137 / 62,8$ & $81 / 37,2$ & 49 \\
\hline 13 & Konidena e Pavani ${ }^{17, b}$ & $15 / 60$ & $10 / 40$ & $\begin{array}{l}F: 47,1 \\
M: 33,1\end{array}$ & - & - & - \\
\hline 14 & Petti et al. ${ }^{27}$ & $310 / 75$ & $103 / 24$ & 44.1 & $371 / 75,3$ & $122 / 24,7$ & 45.2 \\
\hline 15 & Nagao e Sata ${ }^{16}$ & $45 / 76,27$ & $14 / 23,73$ & 68,05 & $60 / 70,58$ & $25 / 29,42$ & 66,35 \\
\hline 16 & Gerayli et al. ${ }^{18}$ & $93 / 69$ & $31 / 30,6$ & 51,6 & $76 / 56,71$ & $58 / 43,29$ & 45,61 \\
\hline
\end{tabular}

F: Sexo Feminino M: Sexo Masculino, MI: Média de Idade.

a: Não descreveu as características demográficas de nenhum dos grupos.

b: Não descreveu as características demográficas do grupo controle.

c: Refere a MI das duas regiões juntas.

†: Refere média para homens e mulheres separadamente. 


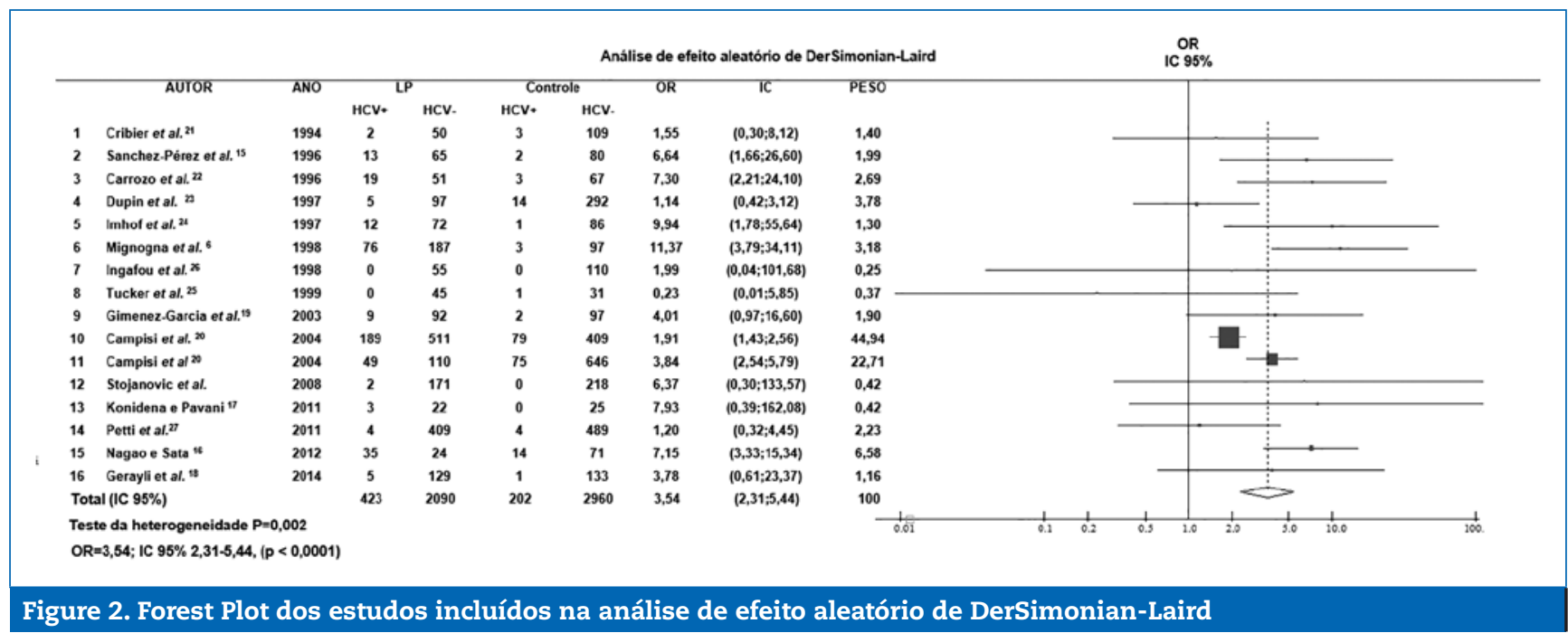

\section{Discussão}

Os resultados encontrados nessa metanálise demonstraram que em pacientes portadores de LP, a chance de ter infeção pelo vírus da hepatite C é 3,54 vezes maior em comparação ao grupo controle $(\mathrm{OR}=3,54)$, o que evidenciou a existência de associação entre o LP e a infeção por HCV. No entanto, dentre os quinze estudos incluídos, oito $10,18,20,21,23,25,26,27$ não encontraram associação significativa entre o LP e o HCV, o que reflete que os resultados encontrados na metanálise diferem de alguns dados da literatura, provavelmente em função do tamanho da mostra estudada.

Os diferentes critérios de seleção dos pacientes dos estudos, o aspeto demográfico e o controle e a exclusão ou não dos pacientes em uso de medicamentos que podem causar reações liquenóides, revelam as diferenças metodológicas de cada estudo de caso-controle. As diferentes características clínicas dos estudos podem ser um fator importante de heterogeneidade de acordo com Berwanger et al, ${ }^{28}$ pois grande parte dos estudos incluíram pacientes de modo consecutivo, 10,15-17,20,21,23,25,26 tendo sido pareados em apenas dois deles. ${ }^{19,22}$

O uso de antivirais e inteferons como drogas para tratamento da hepatite $\mathrm{C}$, de acordo com a literatura, podem gerar reações liquenóides e até mesmo agravar a apresentação clínica do LP. ${ }^{29,30}$ Assim, é importante a exclusão de pacientes em uso de medicamentos capazes de piorar o LP ou gerar lesões semelhantes para reduzir o viés de análise. Dos estudos incluídos, apenas sete relataram a exclusão desses pacientes, ${ }^{10,17,18,21,22,25,26}$ sete não referiram ${ }^{6,15,16,19,20,23}$ e apenas um estudo incluiu pacientes sob tratamento com INF- $\alpha$ devido a diagnóstico prévio de infeção por $\mathrm{HCV}^{24}$

Apesar dos estudos relatarem que a infeção pelo vírus da hepatite C está mais ligada ao tipo clínico do LP, principalmente mucoso, ${ }^{9}$ não foi possível avaliar essa associação, pois apesar da maioria dos estudos incluírem pacientes com LP mucoso, 6,16,18,20,22,23,25,26 existiam estudos que os pacientes apresentavam lesões associadas, ${ }^{10,15,17,19,24}$ ou não relatavam o tipo clínico desta patologia. ${ }^{21}$ Desta forma, é importante realizar mais estudos que comprovem a relação do vírus da hepatite $\mathrm{C}$ ao tipo clínico da manifestação do LP.
Alguns autores relataram que o LP é mais comum em pacientes do sexo feminino. ${ }^{31}$ No presente estudo, não foi encontrada diferença quantitativa desta associação com o Líquen Plano, o que sugere que esta variável não foi relevante na metanálise. Em relação a idade, segundo Campisi et al, ${ }^{20} \mathrm{a}$ prevalência de LP é maior nos pacientes com idade acima de 60 anos, em relação aos pacientes na faixa etária entre 30-39, do mesmo modo que a infeção pelo HCV é crescente na escala de idade. Esta relação não pode ser avaliada no presente estudo, já que os dados de idade dos indivíduos LP positivos infetados pelo HCV, em quase todos os estudos, eram ausentes.

Três metanálises acerca da associação entre o LP e o HCV foram anteriormente realizadas. ${ }^{32-34}$ Lodi et al. ${ }^{33}$ realizaram a análise de subgrupos dos estudos com pacientes com idade igual ou menor que 50 anos e o OR foi semelhante a análise dos estudos com pacientes com 50 anos ou mais, sugerindo que a idade pode não ser um fator importante na prevalência de pacientes com hepatite $C$ e Líquen Plano, o mesmo foi reforçado por Liu $\mathrm{S}$ et al., ${ }^{32}$ que relatou a idade como um fator de confusão.

Os fatores geográficos na associação do LP e HCV foram citados nos três ${ }^{32-34}$ estudos anteriores, revelando que esta influência se deve a distribuição do vírus da hepatite $C$ no mundo. Liu $S$ et at. ${ }^{32}$ relataram que a prevalência de HCV em pacientes com LP foi maior em áreas endêmicas para o vírus, enquanto que Lodi et al. $^{33}$ sugerem que a associação entre LP e HCV não pode ser explicada pela hipótese da diferença de prevalência do vírus. No presente estudo, se observou que tanto em países de baixa prevalência ${ }^{19}$ quanto em países de elevada prevalência do $\mathrm{HCV},{ }^{20}$ a relação estatística era significante. Além disso, em um mesmo país, dois estudos observaram a existência desta relação, ${ }^{6,22}$ e um obteve diferente resultado. ${ }^{20}$

O resultado do OR combinado $(3,54)$ do presente estudo foi menor do que o encontrado pelas metanálises anteriores, ${ }^{32-34}$ entretanto, os trabalhos anteriores incluíram pacientes sem testes confirmatórios para a infeção do HCV, o que provavelmente contribuiu para o aumento da amostra e heterogeneidade dos mesmos.

Atualmente sabe-se que o vírus da hepatite $C$ possui 6 genótipos diferentes, e que seu tratamento varia de acordo com o tipo 
genético.7 Adicionalmente, estudos mostraram que o genótipo do HCV relacionado ao LP varia de acordo com a distribuição no mundo ${ }^{15}$ e não parece ter relação com a apresentação clínica do LP. No atual estudo não foi possível determinar a relação de causa-efeito entre as patologias por falta de dados a respeito do genótipo e devido ao desenho dos estudos incluídos.

Este estudo apresenta algumas limitações, dentre as quais a inclusão de estudos com heterogeneidade clínica. Nesse sentido, os autores utilizaram um método de cálculo para amostras heterogêneas. Se por um lado, os estudos diferem por apresentarem diferentes amostras, com diferenças demográfica e regionais, por outro lado, essa diferença permite uma validação da inferência dos resultados, desde que as limitações do estudo e o método empregado estejam claros. O presente estudo procurou incluir de forma abrangente estudos que evidenciassem ou não a associação de LP com VHC. No intuito de diminuir o viés de resultados, houve a inclusão de estudos que tivessem comprovação diagnóstica das duas patologias em questão, o que torna este estudo relevante e atual.

\section{Conclusões}

A presente revisão com metanálise demonstrou associação entre VHC e LP.

Não foi possível determinar uma relação de causa-efeito entre as duas patologias, devido a metodologia do mesmo.

São necessários estudos que investiguem a fisiopatologia da relação entre o LP e o VHC.

Os resultados desse estudo podem ajudar no manejo da terapêutica do VHC, alertando sobre possíveis reações adversar já que, como é sugerido na literatura, o tratamento do vírus da hepatite $C$ pode gerar e/ou piorar as lesões de LP.

\section{Responsabilidades éticas}

Proteção de pessoas e animais. Os autores declaram que para esta investigação não se realizaram experiências em seres humanos e/ou animais.

Confidencialidade dos dados. Os autores declaram que não aparecem dados de pacientes neste artigo.

Direito à privacidade e consentimento escrito. Os autores declaram que não aparecem dados de pacientes neste artigo.

\section{Conflito de interesses}

Os autores declaram não haver conflito de interesses.

\section{RE F E R Ê N C I A S}

1. Carrozzo M, Gandolfo S. Oral Diseases Possibly Associated with Hepatitis C Virus. Crit Rev Oral Biol Med. 2003;14:115-27.

2. Galossi A, Guarisco R, Bellis L, Puoti C. Extrahepatic manifestations of chronic HCV infection. J Gastrointestin Liver Dis. 2007;16:65-73.
3. Ali A, Zein NN. Hepatitis C infection: a systemic disease with extrahepatic manifestations. Cleve Clin J Med.

2005;72:1005-8,1010-4,1016 passim.

4. Hayat A, Mitwalli A. Hepatitis C and kidney disease. Hepat Res Treat. 2010;2010:534327.

5. Lim HW. Eczemas, fotodermatoses, doenças papulodescamativas (incluindo as fúngicas) e eritemas figurados. In: Goldman L, Ausiello D, editors. Cecil Medicina. 23. ${ }^{a}$ ed. Rio de Janeiro: Elsevier; 2009. p.3400.

6. Mignogna MD, Lo Muzio L, Favia G, Mignogna RE, Carbone R, Bucci E. Oral lichen planus and HCV infection: a clinical evaluation of 263 cases. Int J Dermatol. 1998;37:575-8.

7. Hepatitis C Update July 2016, World Health Organization disponível em <http://www.who.int/mediacentre/factsheets/ fs164/en/>, acedido em 2 de Agosto de 2016

8. Alter MJ. Epidemiology of hepatitis C virus infection. World J Gastroenterol. 2007;13:2436-41.

9. Randazzo AR, Amormino SAF, Martins CR. Líquen plano bucal e hepatite C: Revisão da literatura. Rev Clín Pesq Odontol. 2005;1:37-41.

10. Stojanovic L, Lunder T, Poljak M, Mars T, Mlakar B, Maticic M. Lack of evidence for hepatitis $C$ virus infection in association with lichen planus. Int J Dermatol. 2008;47:1250-6.

11. Van der Meij EH, van der Waal I. Hepatitis C virus infection and oral lichen planus: a report from The Netherlands. J Oral Pathol Med. 2000;29:255-8.

12. Lodi G, Carrozo M, Hallet R, D'Amico E, Piatteli A, Teo CG, Gandolfo S, Carbone M, Porter SR. HCV Genotypes in Italian patients with HCV-related oral lichen planus. J Oral Pathol Med 1997;26:381-4.

13. Lodi G, Scully C, Carrozo M, Griffiths M, Sugerman PB, Thongprasom K. Current controversies in oral lichen planus: report of an international consensus meeting. Part 2. Clinical management and malignant transformation. Oral Surg Oral Med Oral Pathol Oral Radiol Endod. 2005;100:164-78.

14. Nagao Y, Sata M, Ide T, Suzuki H, Tanikawa K, Itoh K, Kameyama T. Development and exacerbation of oral lichen planus during and after interferon therapy for hepatitis C. Eur J Clin Invest. 1996;26:1171-4.

15. Sánchez-Pérez J, Moreno-Otero R, Borque MJ, Rios-Buceta L, García-Díez A. Lichen planus and hepatitis C virus infection: a clinical and virologic study. Acta Derm Venereol. 1998;78:305-6.

16. Nagao Y, S Michio. A retrospective case-control study of hepatitis $C$ virus infection and oral lichen planus in Japan: association study with mutations in the core and NS5A region of hepatitis C virus. BMC Gastroenterology 2012,12:31.

17. A Konidena, BV Pavani. Hepatitis $C$ virus infection in patients with oral lichen planus. Niger J Clin Pract. 2011;14:228-31.

18. Gerayli S, Meshkat Z, Pasdar A, Mozafari P, Banihashemi E, Khajavi M, Rasekhi J. The Association Between Oral Lichen Planus and Hepatitis C Virus Infection; A Report From Northeast of Iran. Jundishapur J Microbiol. 2015;8:e16741.

19. Gimenez-García R, Pérez-Castrillón JL. Lichen planus and hepatitis C virus infection. J Eur Acad Dermatol Venereol. 2003;17:291-5.

20. Campisi G, Fedele S, Lo Russo L, Di Fede O, Aricò P, Craxì A, Mignogna MD. HCV Infection and oral lichen planus: a weak association when HCV is endemic. JViral Hepat. 2004;11:465-70.

21. Cribier B, Garnier C, Laustriat D, Heid E. Lichen planus and hepatitis C virus infection: an epidemiologic study. J Am Acad Dermatol. 1994;31:1070-2.

22. Carrozzo M, Gandolfo S, Carbone M, Colombatto P, Broccoletti $\mathrm{R}$, Garzino-Demo P, Ghisetti V. Hepatitis C virus infection in Italian patients with oral lichen planus: a prospective case-control study. J Oral Pathol Med. 1996;25:527-33.

23. Dupin N, Chosidow O, Lunel F, Fretz C, Szpirglas H, Frances C. Oral lichen planus and hepatitis $C$ virus infection: a fortuitous association? Arch Dermatol. 1997;133:1052-3. 
24. Imhof M, Popal H, Lee JH, Zeuzem S, Milbradt R. Prevalence of hepatitis $C$ virus antibodies and evaluation of hepatitis $C$ virus genotypes in patients with lichen planus. Dermatology. 1997;195:1-5.

25. Tucker SC, Coulson IH. Lichen planus is not associated with hepatitis $C$ virus infection in patients from north west England. Acta Derm Venereol. 1999;79:378-9.

26. Ingafou M, Porter SR, Scully C, Teo CG. No evidence of HCV infection or liver disease in British patients with oral lichen planus. Int J Oral Maxillofac Surg. 1998;27:65-6.

27. Petti S, Rabiei M, De Luca M, Scully C. The magnitude of the association between hepatitis $\mathrm{C}$ virus infection and oral lichen planus: meta-analysis and case control study. Odontology. 2011;99:168-78.

28. Berwanger O, Suzumura EA, Buehler AN, Oliveira JB. Como Avaliar Criticamente Revisões Sistemáticas e Metanálises? Rev Bras Ter Intensiva. 2007;19:192-6.

29. Gheorghe C, Mihai L, Parlatescu I, Tovaru S. Association of oral lichen planus with chronic $C$ hepatitis. Review of the data in literature. Maedica (Buchar). 2014;9:98-103.
30. Simone Garcovich, Matteo Garcovich, Rodolfo Capizzi, Antonio Gasbarrini, Maria Assunta Zocco. Cutaneous manifestations of hepatitis $C$ in the era of new antiviral agentes. World J Hepatol 2015;7:2740-8.

31. Daramola OO, George AO, Ogunbiyi AO. Hepatitis C virus and lichen planus in Nigerians: any relationship? Int J Dermatol. 2002;41:217-9.

32. Liu S, Yao S, Wei W, Tian W, Zhang H, Wang B. Hepatitis C virus and lichen planus: a reciprocal association determined by a meta-analysis. Arch Dermatol. 2009;145:1040-7.

33. Lodi G, Pellicano R, Carrozzo M. Hepatitis C virus infection and lichen planus: a systematic review with meta-analysis. Oral Dis. 2010;16:601-12.

34. Alaizari NA, Al-Maweri SA, Al-Shamiri HM, Tarakji B, Shugaa-Addin B. Hepatitis C virus infections in oral lichen planus: a systematic review and meta-analysis. Aust Dent J. 2016;61:282-7. 